\title{
Affordances of Plurilingual Instruction in Higher Education: A Mixed Methods Study with a Quasi-experiment in an English Language Program
}

\section{${ }^{1, * A n g e l i c a ~ G a l a n t e ~(D) ~}$}

Department of Integrated Studies in Education, Faculty of Education, McGill University, Montréal, QC, Canada H3A 1 Y2

${ }^{*}$ E-mail: angelica.galante@mcgill.ca; website: mcgill.ca/plurilinguallab

\begin{abstract}
While calls have been made for a multi/plural turn in Applied Linguistics, there remains a paucity of research investigating instruction that addresses the turn and its effects on student learning compared with monolingual one-languageonly instruction. This study examines the effects of plurilingual instruction on students' plurilingual and pluricultural competence (PPC) relative to monolingual English-only instruction. Moreover, it investigates potential additional affordances. Seven teachers in an English for Academic Purposes (EAP) program in a Canadian university taught two intact groups for four months: treatment (plurilingual instruction, $n=79$ ) and comparison (monolingual instruction, $n=50$ ) groups. Results from pre- and post-tests of the PPC scale show that students in the treatment group had higher PPC levels over time relative to students in the comparison group. Moreover, analyses of diaries and focus groups with students in the treatment group show that plurilingual instruction offers affordances such as cognition, empathy, and criticality. These results are significant as they suggest that plurilingual instruction may be more effective than monolingual instruction in the development of PPC and it offers several additional affordances.
\end{abstract}

\section{INTRODUCTION}

The multi/plural turn in Applied Linguistics research requires an inclusive $A N D$ integrated view of language. The turn explicitly rejects monolingual or binary perspectives of language learning $A N D$ focuses instead on the interconnectedness of the languages in individuals' repertoires as interdependent $A N D$ not separated (May 2014; Ortega 2014). Several calls have been made to investigate instruction that aligns with the multi/plural turn $A N D$ examine the extent to which it assists with new language learning (Taylor and Snoddon 2013; Kubota 2016), including in English language teaching (Cenoz and Gorter 2013). Two common instructional approaches that have recently gained much attention are translanguaging AND plurilingualism (García and Otheguy 2020; Vallejo and Dooly 2020). In higher education, research on plurilingualism (Lin 2020; 
Preece and Marshall 2020) AND translanguaging (Mazak and Carroll, 2016) shows how students draw on their entire repertoire AND not on one language only to learn content. What is still unknown is the extent to which these approaches differ from monolingual approaches in the development of specific dimensions of communication such as plurilingual $A N D$ pluricultural competence as well as additional potential affordances.

There are still questions as to how theoretical underpinnings of plurilingualism $A N D$ translanguaging are proactively integrated with instructional approaches $A N D$ several issues have been raised. Plurilingualism emerged as a language policy while translanguaging emerged as a pedagogical practice in a bilingual Welsh/English program (García and Otheguy 2020), both in Europe but largely implemented in North America AND other contexts. In the case of plurilingual instruction, scholars have cautioned against the risk of complacency with uncritical neoliberal agendas (Flores 2013; Kubota 2020) AND of topdown implementation of policy that could potentially marginalize speakers of minoritized languages (García and Otheguy 2020). Scholars have also questioned claims often made about translanguaging as being the sole pedagogical approach for social justice in language education (Jaspers 2018), AND that not naming languages in students' repertoires can have detrimental effects on the revitalization $A N D$ maintenance of minoritized languages (Lin et al. 2020). These important critiques were carefully considered in the study reported here by examining colonial $A N D$ neoliberal forces that can marginalize plurilingual speakers; prioritizing students' bottom-up linguistic practices; ensuring that instruction could potentially shift dynamics of privilege by empowering students' repertoires; $A N D$ naming the languages in students' repertoires. The study investigates the affordances of plurilingual instruction $A N D$ adds a quasiexperimental component to examine plurilingual instruction relative to a monolingual English-only approach.

\section{LITERATURE REVIEW}

\section{Plurilingualism}

Plurilingualism is the ever-existing social phenomenon of individuals using different languages to communicate in a fluid way (Canagarajah 2009). It has gained much attention after the publication of policy documents by the Council of Europe, a leading international organization for human rights that promote linguistic $A N D$ cultural diversity in Europe (e.g. Castellotti and Moore 2002; CoE 2006, 2007). Plurilingualism scholars (Moore and Gajo 2009; Piccardo 2020) often use the Council of Europe's (2001) definition of plurilingualism which places emphasis on the individual's repertoire of interconnected languages while multilingualism is used to refer to the co-existence of languages side by side in a given geographical location. As noted by Canagarajah and Liyanage (2012), 'the difference between plurilingualism AND multilingualism is largely theoretical' as the terms refer to 'different ways of perceiving the 
relationship between languages in society $A N D$ individual repertoire' (p. 50). In education, plurilingual instruction emerged to address the social need to prepare individuals to communicate in diverse communities such as diaspora, transnational, $A N D$ digital. Moreover, systemic linguistic, cultural, AND racial discrimination present in many societies (if not all), especially in postcolonial countries, demand an urgent shift in instruction that is inclusive AND emancipatory. Plurilingual instruction can be one pedagogical alternative to address these needs.

The theory of plurilingualism is not new $A N D$ has epistemologically fed upon sociolinguistic concepts such as verbal repertoire (Gumperz 1964) AND communicative competence (Hymes 1972), code-switching (Green and Li 2014), AND translingualism (Canagarajah 2018). While these conceptual frameworks may have developed from different epistemological traditions, they all suggest an urgent need to move away from monolingualism $A N D$ language separation (Dovchin et al. 2018) AND challenge traditional understandings of language as an element of uniformity, homogeneity, AND purity.

When taken up pedagogically, plurilingual instruction encompasses different practices, such as (i) code-switching or alternating between two languages or varieties between sentences or in one single sentence for ease of communication (Green and Li 2014); (ii) translanguaging, or using language fluidly to make sense of the world (García and Otheguy 2020); (iii) plurilanguaging, or using different linguistic $A N D$ semiotic resources for meaning-making (Piccardo 2020); (iv) translating between $A N D$ among languages to mediate language learning (González-Davies 2017); (v) inter-comprehension through the use of one's own repertoire to understand a related language (Candellier et al. 2007]); AND (vi) communicating interculturally (Beacco and Byram 2007). Plurilingualism instruction gained prominence in the 1990s with studies (Coste et al. 2009; its original version in French was published in 1997) that contributed to the conceptualization of the Common European Framework of Reference for languages (CoE 2001), a framework used in language teaching AND learning internationally. In its new volume (CoE 2020), the importance of plurilingual instruction is highlighted through the introduction of new plurilingual $A N D$ pluricultural competence descriptors to guide language teaching AND learning. The cultural dimension in plurilingualism, which may not be as explicit in other language theories, posits that communication across cultures may share similarities $A N D$ differences $A N D$ that adaptation depending on the context, situation, AND interlocutor may be needed (Coste et al. 2009), as discussed below.

\section{Plurilingual and pluricultural competence}

Plurilingual AND pluricultural competence (henceforth PPC) is an important competence to be developed when learning a new language but it is not a new concept. Earlier research on bilingualism (Grosjean 1982), plurilingualism (Lüdi 2004), AND intercultural competence (Beacco and Byram 2007) has been 
influential in the conceptualization of the term. PPC considers individuals' rich repertoires (Lüdi 2004; Rymes 2014; Busch 2017) that are equipped with several semiotic resources (e.g. language, culture, and body), which they activate in intercultural interactions that require flexibility in language use. In PPC, language and culture are integrated (Coste et al. 2009; North and Piccardo 2016; Galante 2020) and both the knowledge and use of language in relation to sociocultural contexts, including language mixing and hybridity, are valued.

Typically, individuals who have high PPC levels are aware of similarities and differences among cultural groups and comfortable navigating between and among cultures (Galante and Dela Cruz 2021). Research on PPC has piqued the interest of scholars who have investigated PPC in language teaching (Chen and Hélot 2018), and policy reform (Savski 2019). To date, no examination investigating whether PPC levels can be developed as a result of instruction has been carried out and this was one of the goals of the study.

\section{Affordances of plurilingual instruction}

Previous research investigating plurilingual instruction has yielded positive results. Most of the studies are exploratory and were conducted in primary or secondary classrooms. For example, Gajo and Steffen (2015) compared two types of instructional approaches in an early French/German bilingual program: one person/one language (monolingual) approach and one person/two languages (plurilingual) approach. Results show that the plurilingual approach enabled students to use both the L1 and L2 flexibly to advance language learning. Corcoll (2013) also found that motivation and self-esteem were positively affected by plurilingual instruction in an English class in Barcelona, where students drew on their repertoire of Spanish and Catalan as a resource to learn English. Other studies found that plurilingual instruction assisted in students' participation in cognitive activities in the classroom (Llompart et al. 2020), and enhanced the development of plurilingual competence and target language proficiency (Stille and Cummins 2013). Moreover, when completing activities such as language biography and identity portraits, studies show that students can develop their plurilingual identities (Stratilaki 2012; Prasad 2014).

Studies in higher education have been conducted in different contexts (see overview in Rubio-Alcalá et al. 2019; Preece and Marshall 2020), but the focus has often been on how individuals use their plurilingual repertoire to support the learning of discipline-specific content, such as Math and Biology. There is little doubt that the repertoire is a key resource for learning but what is still unknown is what type of learning students engage in. Moreover, because of the scarcity of studies investigating the effects of plurilingual instruction relative to monolingual instruction, this study aimed to address these gaps. Two research questions guided the study: 
1 Do EAP students in the treatment (plurilingual) group have higher PPC levels compared with EAP students in the comparison (monolingual) group over time?

2 What are EAP students' perceptions of affordances of plurilingual instruction?

\section{METHOD}

\section{The study}

This was a mixed-methods study that included a quasi-experimental component with treatment and comparison groups in intact Academic Listening and Speaking (ALS) classrooms of an EAP program in Toronto, Canada. As part of a larger investigation of the implementation of plurilingual instruction (Galante et al. 2019) and teachers' perceptions (Galante et al. 2020), the study reported in this article focuses on data gathered from students only.

\section{Participants}

All of the teachers teaching the ALS course were invited to participate. Seven out of nine highly experienced certified ESL teachers volunteered to participate in the study. Six of them had a Master's degree, one had a doctoral degree and one was a doctoral candidate, all in Applied Linguistics or a related discipline. Six of them reported being plurilingual (having two or more languages in their repertoire), and there was a mix of teachers who spoke English as an Ll or additional language. Each teacher had two groups of the ALS course, with the exception of one teacher who had one only group. They were asked to randomly choose their groups as $\mathrm{A}$ and $\mathrm{B}$ and were told that the students in both groups would receive tasks for oral communication. That is, the teachers were aware that the tasks would be similar but unaware of what type of approach students in each group would receive: Group A (treatment, $n=79$ ) would receive plurilingual instruction and Group B (comparison, $n=50$ ) would receive monolingual instruction. The teachers and program director agreed with the design of the study and had no objection.

All of the students whose teachers agreed to participate in the study were invited. There were approximately 10 students in each of the 13 classes and a total of 129 students agreed to participate. They all had international student status and had been admitted in an undergraduate program at the university. Because their English levels did not meet the requirements of the university for direct entry (minimum IELTS score of 6.5), they enrolled in the EAP program. They were all between 18 and 21 years old, and English was their additional language. Most of the students were from China (84\%), and $16 \%$ were from other countries such as Ecuador, Russia, Taiwan, Turkey, and Japan. At the time of data collection, $80 \%$ of the students had been living in Canada for less than a year and $82 \%$ reported being plurilingual, with two or more languages in their repertoire. 


\section{The plurilingual and monolingual instructional approaches}

Both types of instruction refer to 10 weekly tasks of approximately 30-40 min each delivered to the respective groups over 4 months, during the second term of the EAP program: the treatment group received 10 plurilingual tasks while the comparison group received 10 monolingual tasks. The plurilingual tasks engaged students in their repertoire and included strategies such as translanguaging, code-switching, inter-comprehension, cross-linguistic and -cultural comparisons, and translation. The monolingual tasks followed regular English language tasks without the plurilingual strategies. Both sets of tasks had similar linguistic content; for example, the same vocabulary items, idioms, and discourse markers were taught but using different approaches. Moreover, both sets prioritized the same amount of pair and group work. All of the tasks were designed by the researcher in collaboration with the teachers and had a focus on listening and speaking skills to suit the ALS course. Both sets of tasks were provided to the teachers 1 week in advance so that they could provide feedback to the researcher who made modifications whenever needed. The tasks are available at the website www. breakingtheinvisiblewall. com. Table 1 provides a brief description of each task.

\section{Design and procedures}

The study employed pre- and post-tests of the PPC scale (Galante 2018; see Supplementary Appendix 1) at the onset (T1) and 4 months later (T2). I (the author) designed and validated the PPC scale for the study. The process of validation included: (i) identification of scale items based on an extensive review of recent sociolinguistics theories including plurilingualism and translanguaging; (ii) content validation with experts in language education, English language instructors and EAP students; and (iii) construct validation with a series of Exploratory Factor Analysis to determine what factors the scale measured (see Galante 2020 for the validation process of the scale). The PPC scale measures one construct: individuals' perceptions of their plurilingual and pluricultural competence. Students were asked to agree or disagree with 24 items on a 4-point Likert scale. Moreover, data of weekly diaries from students in the treatment group were concurrently collected during the treatment, and focus groups with a purposive sample were conducted at the end of the program. The diaries asked students to enter a short paragraph of their general perceptions of the 10 plurilingual tasks received. Two focus groups of approximately an hour each were conducted with students in the treatment group. Students who had the highest $(n=13)$ and the lowest $(n=13)$ PPC scores at Tl were invited to participate. This choice was made to investigate any possible divergent opinions. Twenty-one students agreed to participate: Focus Group 1 had 12 students and Focus Group 2 had nine students. The questions elicited students' general perceptions of the EAP program such as How do you think the activities completed in class might help you in real life, that is, outside of the classroom? 
Table 1. Description on tasks in each group

Plurilingual tasks

Monolingual tasks

Task $1 \quad$ Linguistic and Cultural Landscape: students explored statistical data about language in Canada and delivered a two-minute monolog in English discussing how different events in their lives helped shape their own linguistic repertoire

Task 2 My Plurilingual Identity: students discussed elements of language and culture in identity formation, drew their linguistic portrait and engaged in small group discussions with peers

Task 3 Code-Switching: students watched a video with people code-switching/ translanguaging in different languages and for different reasons and presented a role-play on the same topic

Task 4 Local and Global Communities: students showcased expressions they knew in different languages, explored how to say Thank You in 30 languages and engaged in roleplays about infusing languages other than English in conversation

Task 5 Idioms in Different Languages: students were presented with 18 English idioms and asked to use their repertoire to guess the meaning. In small groups, they compared idioms across languages and presented a role-play with idioms of their choice, including in other languages

Task 6 Communication Styles: students explored direct and indirect ways to communicate the same message in different situations and engaged in a role-play about solving communication breakdown in academic settings

Task $7 \quad$ Pluricultural Communication: students were presented with eight discourse markers commonly used in oral speech, listened to an audio

Introducing Yourself in an Academic Environment: students explored commonly used language to introduce oneself in academic settings and delivered a two-min monolog in English introducing themselves

\section{Using Diplomacy in Academic}

Discussions: students discussed language that can be used to disagree with others' opinions and engaged in small group discussions with peers

Small Talk Strategies: students were presented with different strategies to engage in small talk and keep the conversation going and presented a role-play on the same topic

Innovation for Social Benefits: students did a quiz on creativity, explored products and services that benefited society in the past 10 years, and engaged in small group discussions of social issues that need innovative services

English Idioms: students were presented with 18 English idioms and asked to look at the definition and match them. In small groups, they wrote sentences with the English idioms and presented a role-play with idioms in English of their choice

\section{Effective Communication in Different} Situations: students explored formal and informal language to communicate the same message and engaged in a role-play about solving issues in collaborative work in academic settings

Using Discourse Markers in Communication: students were presented with eight discourse markers commonly used in oral 
Table 1. (continued)

\begin{tabular}{|c|c|c|}
\hline & Plurilingual tasks & Monolingual tasks \\
\hline & $\begin{array}{l}\text { file about communication across } \\
\text { cultures, and presented a mono- } \\
\text { logue with discourse markers sum- } \\
\text { marizing the content and } \\
\text { discussing their experiences }\end{array}$ & $\begin{array}{l}\text { speech, listened to an audio file } \\
\text { about studying abroad, and pre- } \\
\text { sented a monologue with discourse } \\
\text { markers summarizing the content } \\
\text { and discussing their experiences }\end{array}$ \\
\hline Task 8 & $\begin{array}{l}\text { Intercultural Encounters: students } \\
\text { watched a video with people using } \\
\text { English within different linguistic } \\
\text { and cultural settings, took notes of } \\
\text { language use, and in groups shared } \\
\text { experiences of using English in } \\
\text { intercultural communication }\end{array}$ & $\begin{array}{l}\text { Using Technology in Education: stu- } \\
\text { dents watched a video with six tips } \\
\text { on the use of technology for edu- } \\
\text { cational purposes, took notes of ef- } \\
\text { fective use, and in small groups } \\
\text { shared tips they find useful for aca- } \\
\text { demic purposes }\end{array}$ \\
\hline Task 9 & $\begin{array}{l}\text { Inter-comprehension: students } \\
\text { explored words in different lan- } \\
\text { guages that look and sound similar } \\
\text { and discussed words in English } \\
\text { that were borrowed from other } \\
\text { languages. They also read an aca- } \\
\text { demic abstract in a Canadian jour- } \\
\text { nal in French and tried to guess } \\
\text { the meaning by using their entire } \\
\text { repertoire. The abstract in English } \\
\text { was later presented for comparison }\end{array}$ & $\begin{array}{l}\text { Forming an Opinion: students listened } \\
\text { to an opinion piece of a person } \\
\text { providing different types of argu- } \\
\text { ments to support their opinion for } \\
\text { not visiting zoos. Students took } \\
\text { notes of the types of arguments (e. } \\
\text { g. historical and data) and were } \\
\text { later asked to prepare a monologue } \\
\text { with reasons why they stopped } \\
\text { using a service or product }\end{array}$ \\
\hline Task 10 & $\begin{array}{l}\text { Final Reflection: students were pro- } \\
\text { vided with a sheet summarizing } \\
\text { each plurilingual task received. In } \\
\text { small groups, they were asked to } \\
\text { discuss how the tasks helped with } \\
\text { English listening and speaking } \\
\text { skills and communicating with } \\
\text { others in and outside of } \\
\text { the classroom }\end{array}$ & $\begin{array}{l}\text { Final Reflection: students were pro- } \\
\text { vided with a sheet summarizing } \\
\text { each monolingual task received. In } \\
\text { small groups, they were asked to } \\
\text { discuss how the tasks helped with } \\
\text { English listening and speaking } \\
\text { skills and communicating with } \\
\text { others in and outside of } \\
\text { the classroom }\end{array}$ \\
\hline
\end{tabular}

\section{Analysis}

Following a concurrent embedded design (Teddlie and Tashakkori 2006), data from each set were analyzed separately and later integrated at the discussion level. Both deductive and inductive analyses were used in the study, which prioritized qualitative over quantitative analysis. To answer RQ1, a deductive analysis of the PPC scale data was used. Before the analysis, students' answers to the 24 items of the PPC scale at both $\mathrm{Tl}$ and T2 were tabulated, and negatively worded items were reverse coded. Using IBM SPSS version 25, mean scores were calculated for all 24 items at both $\mathrm{Tl}$ and T2 and a series of statistical analyses was carried out. Cronbach's alpha coefficients were computed to assess internal consistency and scores of 0.73 at $\mathrm{Tl}$ and 0.74 at $\mathrm{T} 2$ indicate acceptable levels. Cronbach's alpha of 0.70 or higher shows that the values of 
internal consistency in the scale are reliable (Nunnally and Bernstein 1994), and this was the case at both times that the scale was used in the study. Further statistical analyses were carried out to investigate any difference in PPC levels between groups and over time.

To answer RQ2, an inductive analysis of diary entries and a deductive analysis of focus groups (secondary confirmatory data) were carried out to examine affordances of plurilingual instruction. Grounded theory (Glaser and Strauss 1967) has been increasingly used in mixed methods research-also called mixed methods-grounded theory-to fuse dialectical pluralism into the classic pragmatism of this type of research (Guetterman et al. 2019), and it was used to analyze the diary entries, a total of 672 (of $91 \%$ of diaries collected). The analysis was carried out in NVivo 1.1. Following a systematic approach (Cohen and Manion 2007), three types of coding were used: initial (reading line by line and assigning codes for emergent topics); axial (comparing the coding, finding patterns, and establishing connections among them); and selective (selecting codes from the initial coding, applying to the remaining of the data, and further refining them). When saturation was achieved, the coding process ended. Furthermore, focus group data were analyzed deductively, based on the predetermined categories of diary data, to supplement the results.

\section{RESULTS}

The results are presented below according to the research questions.

RQ1: PPC levels among students in the plurilingual and monolingual groups

The first RQ aimed to investigate whether students in the treatment group (plurilingual instruction) would have higher PPC levels compared with students in the comparison group (monolingual instruction) over time.

A repeated-measures ANOVA was conducted to find out whether there were differences in PPC levels over time and between groups. The ANOVA included PPC (one level) and Time (two levels) as within-subject factors and Group as the between-subject factor. Results revealed significant effects for Time and a significant Time Group interaction. The effect of Time, $F(1,127)=$ 29.07, $p<0.001$, partial ${ }^{2}=0.19$, indicates that PPC levels significantly improved between T1 $(M=2.96, S D=0.31)$ and T2 $(M=3.10, S D=0.30)$ for all student participants combined. The Time Group interaction, $F(1,127)=$ 5.94, $p=0.016$, partial $^{2}=0.045$, indicates that PPC levels changed over time differently between groups. Figure 1 illustrates PPC levels across groups and over time. The scale ranged from 1 to 4 , with higher numbers indicating higher levels of PPC.

The figure shows that PPC levels among participants from both groups were similar at T1, indicating students in both groups had similar levels of PPC: scores were $M=2.97(S D=0.30)$ for participants in the treatment group and $M=2.95$ 
3.5

- Plurilingual Group

- Monolingual Group

\section{3}

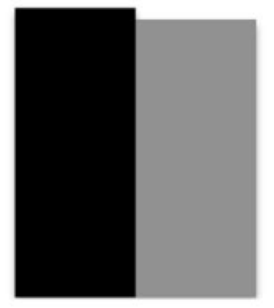

Time 1

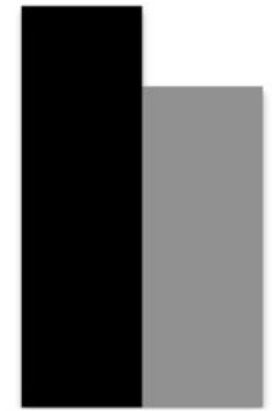

Time 2

Figure 1: PPC levels between groups and over time.

$(S D=0.32)$ for participants in the comparison group. At T2, however, scores were $M=3.15(S D=0.28)$ for participants in the treatment group and $M=3.02$ $(S D=0.32)$ for participants in the comparison group, indicating higher levels for students in the treatment (plurilingual instruction) group over time.

To confirm the significance of this result, post hoc independent samples $t$-tests were conducted to probe the Time Group interaction. There was no significant difference between treatment $(M=2.97, S D=0.30)$ and comparison groups $(M$ $=2.95, S D=0.32)$ at $\mathrm{Tl}, t(127)=0.33, p=0.74$, confirming that both groups had similar PPC levels at the start of the EAP program. At the end of the program, or T2, there was a significant difference in PPC scores between treatment $(M=3.15, S D=0.28)$ and comparison groups $(M=3.02, S D=0.32)$ at $\mathrm{T} 2, t(127)$ $=2.52, p=0.013$, indicating that PPC levels among participants in the treatment group were significantly higher after receiving plurilingual instruction compared with participants in the comparison group who received monolingual instruction. These results suggest that over time, or four months later, students in the plurilingual instruction group improved PPC scores significantly compared with students in the monolingual instruction group. This increase may be due to the type of instruction but a further examination of the affordances of plurilingual instruction may explain this increase in PPC scores.

\section{RQ2: Affordances of plurilingual instruction}

The second RQ examined affordances of plurilingual instruction from students' viewpoints. Nine affordances were found, as summarized in Table 2 and further discussed below. The quotes are representative of each affordance. 
Table 2. Nine affordances of plurilingual instruction

Affordances

Number of occurrences

1. Cognition: mental processes to develop knowledge and understanding of language and culture

2. Awareness of plurilingual and pluricultural identity: recognition that languages and cultures shape one's identity

3. Flexible language use: practices such as code-switching, translanguaging, plurilanguaging, and inter-comprehension

4. Additional language and cultural learning: knowledge of languages and cultures that are not necessarily related to the English language (the target language of the EAP program)

5. Critical awareness of societal multilingualism and multiculturalism: recognition of power relations among languages and cultures at the social level

6. English language learning: linguistic dimensions of English such as grammatical structures, lexical items, semantics, phonology, and pragmatics

7. Empathy: the ability to understand and share other people's feelings and emotions as if they were their own

8. Relatability: the ability to establish associations based on aspects that are easy to understand and feel connect to

9. Criticality: the ability to analyze issues and evaluate information from different viewpoints to formulate reasoning

\section{Cognition}

The first affordance of plurilingual instruction was cognition. The plurilingual tasks invited students' reflection on differences and similarities among languages and cultures on different dimensions: pronunciation, written form, and linguistic behaviors, among others. When comparing the pronunciation and written forms of words in different languages, students analyzed patterns across languages; for example, through inter-comprehension (Candellier et al. 2010) they recognized that certain European languages have similar pronunciation for the expression 'thank you': 
These are three languages that have the same pronunciation, which is quite interesting: they are respectively Danish (tak), Swedish (tack) and Norwegian (takk).

Besides pronunciation and graphic representations, another cognitive strategy used when comparing languages was reasoning. Many of the students made comparisons between English idioms and idioms in their L1, but also learned about idioms in the languages of their peers. Some of these comparisons required reflection on meaning-making across languages and semiotic resources, or plurilanguaging (Piccardo 2020), both identification of literal and figurative meanings, and cultural understandings. For example, students reported that many idioms in English can be translated into Chinese and other languages but the number of Chinese idioms is often longer. Students, however, used more than L1-L2 comparisons: the plurilingual tasks harness engagement with all of the languages and dialects in their repertoire and the repertoire of their peers who many times had different languages.

Cognition through comparisons of communication styles was another result found and many students engaged in understanding language use in different contexts:

In Canadian culture, I use please/could you please, do you mind...to the teacher and Prof. Also, in Chinese culture, I use Nin (您') instead of Ni (你) when we talk to the Prof. These two words have the same meaning but Nin (您) is high level.

Students often reported that after engaging in plurilingual tasks, they were able to identify communication breakdown as a result of language use in relation to culture, interlocutor, context, and situation, which is an important skill for the development of intercultural communication (Beacco and Byram 2007).

Data from the focus groups show that students repeatedly noted that comparison processes enhanced their understanding of language variation. After some debate, they concluded that the knowledge gained about variation in language use could be transferable to real-life situations. Overall, these results provide further evidence that the plurilingual tasks enhanced cognition.

\section{Plurilingual and pluricultural identity}

The second affordance found was awareness of plurilingual and pluricultural identity. Results reveal that aspects such as place of birth, national language policies, the language of instruction in schools, travel, interests, and globalization shaped students' repertoire; for example, given the popularity of English as an international language and Chinese as a language mandated by local policies, students who were born in China recognized that they did not have much of a choice but to learn both languages. Other aspects such as heritage, job opportunities, media, and the arts were also noted as influencing students' awareness. 
Tasks such as language biography (Stratilaki 2012) and identity portraits (Prasad 2014) enhanced students' understanding of their identity, and students recognized not only how their plurilingual but also pluricultural trajectories shaped their identity. They noted that aspects that had been previously ignored as influencing their repertoire-such as art, games, movies, TV shows, and animes - also played a key role in their identity development. This empirical finding exemplifies the theoretical concept of communicative repertoire (Lüdi 2004; Rymes 2014; Busch 2017).

Besides language, many students recognized that a mix of cultures can be part of one's identity, challenging monocultural assumptions previously held. Many Chinese students noted that before engaging in the plurilingual tasks, they considered themselves as having a pure Chinese identity, a view that changed over time. An important observation made by some Chinese students was that they do not need to give up their Chinese identity to embrace others. Moreover, the students also held the strong position that everyone is pluricultural, as noted below:

I think all of us are pluricultural. For example, in my heart I am Chinese. But the way of how I think is English. Moreover, because I like Japanese culture, Japanese can be part of my body. I had learned some new words from my colleague which is a Russian male. Learning different words given me the feeling that I am close to other culture.

The linguistic and cultural dimension inherent in PPC (Coste et al. 2009) was reflected in students' identities. Moreover, many Chinese students noted that even within the broader culture of a country, diversity occurs, 'Even though we come from the same country, we still have some different culture'. This observation was reiterated by students from other countries such as Ecuador; in contrast to the Chinese students who highlighted differences among minority and majority cultures in China, the Ecuadorian students pointed out the cultures of the Indigenous and immigrant populations in their country. These results support the importance of culture in the plurilingual theory, which may not be explicitly present in other language theories.

\section{Flexible language use}

The third affordance of plurilingual instruction was students' recognition of flexible language practices: translanguaging as the fluid use of the linguistic repertoire (García and Otheguy 2020), code-switching as the alternation of linguistic codes (Green and $\mathrm{Li}$ 2014), and inter-comprehension as the ability to understand a language by using the entire linguistic repertoire (Candellier et al. 2010). Students often reported that these practices are ordinary and recurrent in their daily lives, and argued that they deliberate use them to make communication more effective and faster than using one language only.

Besides, students also noted that the fluid use of languages was helpful for meaning-making, which has been supported theoretically with the concepts 
of translanguaging (García and Otheguy 2020) and plurilanguaging (Piccardo 2020). This fluid use for meaning-making was particularly relevant when learning new concepts, as was the case of idioms in English:

The task made me found a lot of Taiwanese idioms that I never knew before. I found the idiom that had similar meaning 'have a chip on your shoulder' is '久水怨天公, 愛睏怨南風'. My classmates discussed some idioms in Mandarin, Cantonese, Russian and Spanish. It was fun to listen to some different languages.

A focus on the meaning of idioms across languages (plurilanguaging), and not only two, was recurrent in student diaries. Often, students reported that making connections among languages to understand content were more effective than using English only. Inter-comprehension was another strategy that emerged in the diary data. Students noticed that even among people who have not formally studied a language, they are able to partially understand a new language:

\section{Although all of us did not know French, we can still guess the major meaning of the words because some of them were same or similar to English words.}

Translanguaging practices were often used during the focus group for meaning-making. One example took place during the focus group, where one student discussed his experiences learning Manchu, a heritage language he spoke with his grandfather. He first talked about Chinese dynasties in Chinese and later explained it in English but maintained the original names of the dynasties in Chinese. These and other flexible practices reported here may have contributed to students' development of PPC.

\section{Additional language and cultural learning}

The fourth affordance of plurilingual instruction was additional language and cultural learning. Results show that students were given opportunities to learn words and expressions in languages other than English as well as cultural knowledge from their peers and teachers. For example, one of the tasks required that students listen to the expression 'thank you' in different languages and make comparisons across languages. Many students reported being motivated to hear different languages, and recognize some of them (inter-comprehension). This finding was metaphorically summarized by a student, 'I think this task really broadens my horizon'. Many of the students who spoke Chinese reported being happy to be able to understand 'thank you' in Cantonese, Korean, and Japanese, while one Turkish-speaking student noted she was able to identify that 'thank you' in Turkish and French are spelt similarly, with a slight difference in pronunciation. Overall, students expressed satisfaction when understanding their own Ll and other additional languages, as rightly expressed by a student, speaker of Spanish as a L1: 
Speaking in another language made me feel so smart no matter if I am not (jaja). It was really interesting to know from other languages and understand other people say thank you in other languages, especially in Spanish. I've learned some words in Chinese and in other languages such as Russian.

Other students wrote that they made an extra effort to learn words in languages spoken by their peers so that they could practice when meeting them: 'I specially memorized the pronunciation in Chinese and Russian language because of my classmates (xièxiè $\theta$ spasibo). I felt excited learning one word in different languages'. The languages of their peers were typically the ones students expressed willingness to learn. Moreover, they often expressed satisfaction in teaching their peers about the languages in their repertoire, especially to the teachers who were not fluent speakers of their languages.

Language learning is strongly linked to cultural learning, which supports the interrelatedness of language and culture in the concept of PPC (Coste et al. 2009) and many students reported a willingness to be 'influenced' by the culture of their peers, arguing that it helped them be more open-minded and accepting of new ideas. Among students from the same country, learning about other dialects and cultural diversity was often reported as new cultural learning, and allowed them to internally examine their own cultural biases. Thus, learning more than just English in the EAP program may have assisted in students' development of PPC.

\section{Critical awareness of multilingualism and multiculturalism}

The fifth affordance of plurilingual instruction, and a new one in the literature, was critical awareness of multilingual and multicultural landscapes. Here, the notion of multilingualism relates to the presence of several languages existent in society (CoE 2001) rather than plurilingualism as the social phenomenon of people using different languages to communicate (Canagarajah 2009). Students had opportunities to reflect on languages present in the city where they lived in, in Canada, and in other countries. Some students reported being surprised at the number of languages spoken in different cities, such as Toronto:

There are more than 50\% people whose native language is not English or French in Toronto. That means I don't need to be uncomfortable of speaking English because I'm not the 'minority'.

For some students, speaking English with a native speaker constituted a source of anxiety and the fact that multilingualism is inherent in the Canadian landscape made them feel more comfortable given that interactions in English also occur among non-native English speakers. Moreover, students reported being unaware of the languages and dialects spoken by their classmates until they completed the plurilingual tasks, 'I have been in the same class 
with these students for such a long time and I didn't know that China has totally different dialects from province to province'.

Another result related to the many Indigenous languages spoken in Canada and other post-colonial countries. For many students, particularly the ones from China, learning about Canada's Indigenous languages and the process of colonization was novel but for students from postcolonial countries (e.g. Ecuador) it was simply a reminder of a similar process in their countries. Importantly, the students expressed critical awareness of the genocide of Indigenous languages and explained that the plurilingual tasks raise awareness to Canada's many languages and the need to learn about cultural diversity and not only what students thought of as 'Canadian culture'.

In the focus groups, some students added that the plurilingual tasks allowed them to recognize that racism and discrimination against Indigenous and Black communities are a result of colonial legacy, which is embedded in Canadian multiculturalism:

We learned about racism, actually I think this is part of the culture and also, we learn the history or colonization about different culture that has suffered many events. I think it gives you a chance to know other cultures through the learning the history and some problems that exist in the society (Focus Group 2).

Students further discussed tensions between immigrant groups and Canadianborn residents, the lack of respect for Indigenous people's rights, and frequent carding - random police questioning requesting personal information with no reasonable grounds-among Black residents in Toronto. These observations are important as previous scholars have raised questions about the risk of implementing plurilingualism uncritically (Kubota 2020) and complacently with neoliberal agendas (Flores 2013), which can leave systemic racism and discrimination unexplored.

\section{Empathy}

The sixth affordance, which is another novel dimension addressed in the literature, of plurilingual instruction was empathy. Results show that students developed empathy, particularly toward linguistic and cultural differences and expressed the need to be understanding of different values, behaviors, and ways of thinking.

While students had been studying with others as a cohort for four months before the data collection, it was only after taking part in the plurilingual tasks that they reported awareness of the role of empathy in intercultural communication. Moreover, learning about their peers' cultural backgrounds helped them both empathize with their peers' views and be less judgemental. For them, empathy and cultural understandings are crucial for successful communication among people from different backgrounds, supporting previous literature on intercultural communication (Beacco and Byram 2007). 
Language use, or more specifically using words and expressions in the languages of the interlocutors, was also considered important when establishing empathy:

I feel the desire to learn more about the world because outside our site of comfort we have new people, a new world to discover in each new language that is useful for ourselves due to the fact that we are going to see toward the differences and attitudes to a state in which you don't see the other person as different, but as part of you.

Similar results were found in the focus groups: some students pointed out that the tasks afforded opportunities to discuss issues of discrimination in intercultural communication. For example, when listening to the word 'Chino' from his fellow Ecuadorian colleague, a Chinese student explained that he felt the urge to teach his colleague that the term is disrespectful toward Chinese people:

It's not a very positive word and also sometimes he uses impressions like put his hands around his eyes to do like to show it's Chinese and we also told him that this is not really polite for us. He feels really bad for doing that and he will not do it again in the future (Focus Group 2).

While the term 'chino' may in a purely linguistic sense represent a male Chinese person in Spanish, depending on the context and interlocutor, which was the case in this study, the term is racist. These discussions allowed the Ecuadorian student to learn from this experience and show empathy. Once again, the critical dimension of plurilingual instruction was important (Kubota 2020) as the evaluation of language in relation to race became an invaluable affordance in the development of empathy.

\section{English language learning}

The seventh affordance of plurilingual instruction was learning English, which was the target language of the EAP program. Two tasks, in particular, focused on English idioms and discourse markers and while the monolingual tasks had the same linguistic focus, the plurilingual tasks engaged students in learning English by deploying their repertoire (Rymes 2014) as a resource for new learning. For example, many students reported that analyzing similarities in the use of discourse markers across languages (plurilanguaging) contributed to better understandings of how to use them in English, as exemplified by a student:

In Canadian culture, people are used to using transition words during the conversation to make idea logical. I think this task is very helpful because in China, the transition words are very different from Canadian culture. This task is helpful for both my speaking and writing. It can help me speak and write more logical. 
Another interesting result related to students noticing that communication in a multilingual and multicultural setting is unlikely to be 'pure', and that being open to learn English dialects and different pronunciations is essential for communication. When asked about activities in the EAP program that helped them in real-life communication, students mostly reported that the plurilingual tasks were helpful:

Different people have different ways of $u$ h talking and they may express their opinions uh very strict or maybe they are uh more indirect so the knowledge I learned helped me contribute speaking English in real life (Focus Group 1).

Openness to learn different varieties of the same language is an important dimension of plurilingual and pluricultural competence (Coste et al 2009) and was well reflected in these results.

\section{Relatability}

The eighth affordance of plurilingual instruction found was relatability, which was also a novel result. Students often reported that plurilingual tasks contributed to developing close connections with others through practices such as translanguaging, code-switching, inter-comprehension, and learning the language of their peers. Switching languages was particularly argued to enhance connections between people and enhance friendship.

Similarly, some students also noted that code-switching can establish ' a sense of belonging' and 'close connections with others because some words/expressions have not translation equivalent'. It is worth noting that students recognized that codeswitching can occur even if a speaker has limited proficiency in one of the languages and maintained the benefits of code-switching for establishing relations with others. This unbalanced proficiency in the languages in one's repertoire is considered normal in the plurilingual theory (CoE 2001).

Results also show that using the language(s) of the interlocutors instead of English as a lingua franca can have a positive effect. For some students, speaking the language of their peers represented going beyond a willingness to communicate to the willingness to connect, as summarized by a student: 'Learning words from other languages like Korean made a bridge between me and my Korean friend after doing this task'. Moreover, students' reports show that this phenomenon provides a two-way benefit, positively affecting both the speaker and the listener: 'It is really exciting to say gracias to my Spanish classmate. She became happy and feel closer to me when I said some Spanish words'.

A similar feeling was reported when students and their colleagues started learning words in a language other than English. During the focus group, students pointed out that small group discussions during the tasks afforded the opportunity to talk to students from other racial, cultural, and linguistic backgrounds and connect with them through their stories and lived experiences. 


\section{Criticality}

The ninth and final affordance of plurilingual instruction was criticality, which is also a new result in the literature. Results indicate that the tasks required critical examinations of language and culture from different traditions, historical accounts, as well as the lived experiences shared by students. For example, some of the analyses were related to the extinction of many dialects in China because of language policies that favour linguistic uniformity:

In the whole China, there were many different versions of Mandarin. However, after the government promote Mandarin, some of the versions (dialects) are missing and no longer exist. Promoting Mandarin can make communication easily but it also hurt the diversity of language.

Other students, for example, argued that China had been bombarded by cultural influences from America, Europe, Japan, and Korea, which directly impacted Chinese culture. While some Chinese students expressed interest in the Korean language, TV drama, and pop music, others pointed out that this interest may be due to the Chinese government's attempts of colonialism over South Korea through China's appropriation of South Korean culture. During the discussions afforded by the plurilingual tasks, some students critically evaluated the positive and negative aspects of different cultures and concluded that pluriculturality is preferred.

Before engaging in the plurilingual tasks, some students reported being unaware of the connections between language and culture, as suggested in the concept of PPC (Coste et al. 2009). Similar results were found in focus groups data, which reveal that the plurilingual instruction enhanced criticality on several topics such as language policies, racism, language use, and linguistic and cultural discrimination, in Canada and other countries. These critical dimensions are important in plurilingual instruction because an examination of language in relation to issues such as power relations and discrimination can assist language users in developing social agency (Kubota 2020). One Chinese student observed the political tensions between China and Taiwan and admitted that after a discussion during a plurilingual task, his opinion changed:

\section{There's a girl from Taiwan so I think in mainland China people think of Taiwan as part of China, because we accept this knowledge from the text- book, but maybe in Taiwan it's like different because of some political problems. So, we talked to her and we realized that maybe next time we talk to people who are from Taiwan we will realize and try to pay attention to not bother them (Focus Group 2).}

Changing viewpoints during the completion of the plurilingual tasks may have contributed to changing PPC scores over time. For example, item 14 in the scale is 'It is easy for me to talk to people from other cultural backgrounds, and discuss similarities and differences in points of view' and it could be that the level of 
agreement in this and other items changed as a result of the critical discussion afforded by the plurilingual instruction.

\section{DISCUSSION AND CONCLUSION}

In response to several calls in Applied Linguistics research to examine instruction that aligns with the multi/plural turn, the overarching goal of the research was to investigate affordances of plurilingual instruction in higher education.

The results suggest that plurilingual instruction has significant positive effects on students' PPC levels relative to monolingual instruction. This positive effect was probably linked to students' recognition of their plural identities, a validation of flexible language practices, and their engagement in critical discussions of language and culture. The results confirm findings of previous research that suggests that plurilingual instruction validates students' flexible language use (Corcoll 2013; Gajo and Steffen 2015), enhances English language learning (Stille and Cummins 2013), allows the mobilization of resources in the completion of cognitive activities (Llompart et al. 2020), and develops students' plurilingual identities (Stratilaki 2012; Prasad 2014). Unique to the study's results, however, were six additional affordances found: additional language and cultural learning, awareness of societal multilingualism and multiculturalism, empathy, relatability, and criticality. The grounded theory analysis of rich qualitative data may have contributed to a fine-grained investigation that found these additional affordances. It could also be that these results were found because of the context (postcolonial Canada), or the tasks for provoking students to critically discuss Canada's linguistic genocide, and their lived experiences with racism, among other issues.

From a pedagogical perspective, the results of the study are important as they show that even in classes where only one target language (English) is the focus, plurilingual instruction can be effectively infused into the curriculum. While the results of this study are solely based on students' voices, the participating teachers unanimously reported a preference for plurilingual instruction compared with monolingual instruction (Galante et al. 2020). The plurilingual instruction in this study was delivered in the form of weekly language tasks that suited the needs of the EAP program and this decision was made in collaboration with the program director and the teachers to avoid major disruptions (Galante et al. 2019). Therefore, future classroom research with a quasiexperimental component may follow similar directions to those that proved effective in our context but collaborating with teachers in the decisionmaking process is an important aspect to be considered.

From a research perspective, several questions remain unanswered and deserve further investigation: does plurilingual instruction have a positive effect on English language scores, such as standardized tests (e.g. IELTS and TOEFL) which are often required in English-speaking universities as proof of language proficiency? Would results of pre-and post-tests of English proficiency scores in 
a research study comparing both monolingual and plurilingual instruction be an appropriate and even ethical measure considering these tests are strictly monolingual and may limit student engagement with their repertoire? Scholars have begun investigating the challenges of non-monolingual assessment (Lopez et al. 2017, Schissel et al. 2018), and more studies are urgently needed in this area.

This study had limitations, which were somewhat expected given the complexity of classroom research. It is worth noting that the quasi-experimental component of the study controlled several variables to increase the reliability of the results: both types of instructional approaches had the same teacher, amount of time, linguistic content, exposure to listening and speaking practice, and interactional strategies. While the increase in PPC scores may have been due to the plurilingual instruction, it could be that extraneous variables such as languages used outside of the classroom, and discussion topics had an effect on this increase. Moreover, given that no qualitative data were gathered from students in the monolingual group, more research investigating these affordances in relation to monolingual instruction is needed. Finally, while the PPC scale had acceptable levels of reliability-Cronbach's alpha coefficient of 0.72 and 0.74 at $\mathrm{T} 1$ and T2, respectively, a second and improved version of the scale suggests higher levels-at 0.84 (see Galante 2020). Therefore, future research should include the most recent version of the scale.

While the study focused on the affordances of plurilingual instruction, two challenges were identified but they were not related to the instruction: challenges in finding translation equivalents across languages and the need to stick to one language only depending on the interlocutor, particularly with native speakers of English who do not speak or are not open to other languages. Future research should not ignore the potential challenges of plurilingual instruction as they can emerge with different student populations, programs, teachers, and other variables.

To conclude, given that plurilingualism in a social reality (Canagarajah 2009) and that PPC is a competence that is relevant for communication in times when migration, mobility, and technology have diversified our landscapes (Coste et al. 2009), future research investigating instruction that addresses this social reality is much needed. The results of the study reported here suggest that plurilingual instruction has several affordances which monolingual instruction may not have; thus, future research may replicate the quasi-experimental component of this study to confirm or refute the PPC results reported here and further examine other affordances and potential challenges in other contexts.

\section{ACKNOWLEDGEMENTS}

I would like to thank all of the participants, EAP instructors, and the program director for making this study possible. 


\section{SUPPLEMENTARY DATA}

Supplementary material is available at Applied Linguistics online.

\section{CONFLICT OF INTEREST STATEMENT}

None declared.

\section{FUNDING}

This study was funded by a doctoral grant from the Social Sciences and Humanities Research Council of Canada (752-2016- 1063), the 2016 Doctoral Dissertation Grant for research on plurilingualism from the International Research Foundation for English Language Education, the 2017 Senior Doctoral Fellowship from the International Foundation Program at New College/University of Toronto, and the 2018 Multilingual Matters Award at the American Association for Applied Linguistics.

\section{REFERENCES}

Beacco, J.-C. and M. Byram. 2007. From Linguistic Diversity to Plurilingual Education: Guide for the Development of Language Policies in Europe. Council of Europe, accessed in July 30, 2021, from https:// rm. coe. int/ CoERMPublicCommonSearchServices/ DisplayDCTMContent?documentId= $09000016802 \mathrm{fclc} 4$

Busch, B. 2017. 'Expanding the notion of linguistic repertoire: On the concept of Spracherleben -The lived experience,' Applied Linguistics 38/3: 340-58.

Canagarajah, S. 2009. 'The plurilingual tradition and the English language in South Asia,' AILA Review 22/1: 5-22.

Canagarajah, S. 2018. 'Translingual practice as spatial repertoires: Expanding the paradigm beyond structuralist orientations,' Applied Linguistics 39: 31-54.

Canagarajah, S., and I. Liyanage, 2012. 'Lessons from pre-colonial multilingualism' in $\mathrm{M}$. Martin-Jones, A. Blackledge, and A. Creese. (eds): The Routledge Handbook of Multilingualism. Routledge, pp. 49-65.

Cadelier, M., A. Camilleri-Grima, V. Castellotti, J.-F. de Pietro, I. Lörincz, F.-J. Meissner, A. Schröder-Sura, A. Noguerol, and M. Molinié. 2010. Framework of Reference for Pluralistic Approaches to Languages and Cultures. Council of
Europe, accessed in July 30, 2021, from https:// carap. ecml. at/ Portals/ 11/ documents/ CARAPversion3-EN- 28062010. pdf.

Castellotti, V. and D. Moore. 2002. Social Representations of Languages and Teaching: Guide for the Development of Language Education Policies in Europe from Linguistic Diversity to Plurilingual Education. Council of Europe, available at https:// rm. coe. int/ social- repre sentations- of- languages- and- teach ing/ 1680872d02.

Cenoz, J. and D. Gorter. 2013. 'Towards a plurilingual approach in English language teaching: Softening the boundaries between languages,' TESOL Quarterly 47: 591-9.

Chen, Y.-Z. and C. Hélot. 2018. "The notion of plurilingual and pluricultural competence in the teaching of foreign languages in France,' Language Education and Multilingualism 1: 168-87.

Cohen, L., L. Manion, and K. Morrison. 2007. Research Methods in Education, 6th edn. Routledge.

Corcoll, C. 2013. 'Developing children's language awareness: Switching codes in the language classroom,' International Journal of Multilingualism 10: 27-45.

Coste, D., D. Moore, and G. Zarate. 2009. Plurilingual and Pluricultural Competence: Studies Towards a Common European Framework of 
Reference for Language Learning and Teaching. Council of Europe, available at https:// rm. coe. int/ 168069d29b.

Council of Europe. 2001. Common European Framework of Reference for Languages. Council of Europe, available at https:// rm. coe. int/ 16802fclbf.

Council of Europe. 2006. Plurilingual Education in Europe: 50 years of International Co-operation. Council of Europe, available at https:// www. ecml. at/ Portals/ 1/ documents/ CoE- docu ments/ plurinlingaleducation_en. pdf

Council of Europe. 2007. From Linguistic Diversity to Plurilingual Education: Guide for the Development of Language Education Policies in Europe. Council of Europe, accessed in July 30, 2021, from https://rm. coe. int/CoERMPublicCommonSearchServices/ DisplayDCTMContent?documentId $=090000168$ $02 \mathrm{fclc} 4$.

Council of Europe. 2020. Common European Framework of Reference for Languages: Companion Volume with New Descriptors. Council of Europe, available at https:// rm. coe. int/ common- euro pean- framework- of- reference- for- languageslearning-teaching/ 16809ea0d4.

Dovchin, S., A. Pennycook, and S. Sultana. 2018. 'Transglossia: From translanguaging to transglossia,' in S., Dovchin, A. Pennycook and S. Sultana (eds): Popular Culture, Voice and Linguistic Diversity. Language and Globalization. Palgrave MacMillan, pp. 27-56.

Flores, N. 2013. 'The unexamined relationship between neoliberalism and plurilingualism: A cautionary tale,' TESOL Quarterly 47: 500-13.

Gajo, L. and G. Steffen. 2015. 'Didactique du plurilinguisme et alternance de codes: Le cas de l'enseignement bilingue précoce,' The Canadian Modern Language Review 71: 471-99.

Galante, A. 2018. Plurilingual or monolingual? A mixed methods study investigating plurilingual instruction in an EAP program at a Canadian University, Doctoral thesis, University of Toronto, available at https:// hdl. handle. net/ 1807/ 91806.

Galante, A. 2020. 'Plurilingual and pluricultural competence (PPC) scale: The inseparability of language and culture,' International Journal of Multilingualism https:// doi. org/ 10. 1080/ 14790718. 2020. 1753747

Galante, A., K. Okubo, C. Cole, N. A. Elkader, N. Carozza, C. Wilkinson, C. Wotton, and J. Vasic. 2019. 'Plurilingualism in higher education: A collaborative initiative for the implementation of plurilingual tasks in an English for Academic Purposes program at a Canadian university,' TESL Canada Journal 36: 121-33.

Galante, A., K. Okubo, C. Cole, N. Abd Elkader, C. Wilkinson, N. Carozza, C. Wotton, and J. Vasic. 2020. 'English-only is not the way to go: Teachers' perceptions of plurilingual instruction in an English program at a Canadian university,' TESOL Quarterly 54: 980-1009.

Galante, A. and J. W. N. Dela Cruz. 2021. 'Plurilingual and pluricultural as the new normal: An examination of language and identity in the multilingual city of Montréal,' Journal of Multilingual and Multicultural Development https:// doi. org/ 10. 1080/ 01434632. 2021. 1931244

García, O. and R. Otheguy. 2020. 'Plurilingualism and translanguaging: Commonalities and divergences,' International Journal of Bilingual Education and Bilingualism 23: 17-35.

Glaser, B. G. and A. L. Strauss. 1967. The Ecological Approach to Visual Perception. Erlbaum.

González-Davies, M. 2017. 'The use of translation in an integrated plurilingual approach to language learning: Teacher strategies and best practices,' Journal of Spanish Language Teaching 4: 124-35.

Green, D. and W. Li. 2004. 'A control process model of code-switching,' Language Cognition and Neuroscience 29: 499-511.

Grosjean, F. 1982. Life with Two Languages: An Introduction to Bilingualism. Harvard University Press.

Guetterman, T. C., W. A. Babchuk, M. C. Howell Smith, and J. Stevens. 2019. 'Contemporary approaches to mixed methods-grounded theory research: A field-based analysis,' Journal of Mixed Methods Research 13: 179-95.

Gumperz, J. J. 1964. 'Linguistic and social interaction in two communities,' American Anthropologist 66/6: 137-53.

Hymes, D. 1972. 'On communicative competence,' in J. Pride and J. Holmes (eds): Sociolinguistics. Penguin, pp. 269-93.

Jaspers, J. 2018. 'The transformative limits of translanguaging,' Language and Communication 58: $1-10$.

Kubota, K. 2016. 'The multi/plural turn, postcolonial theory, and neoliberal multiculturalism: Complicities and implications for Applied Linguistics,' Applied Linguistics 37: 474-94. 
Kubota, K. 2020. 'Promoting and problematizing multi/plural approaches in language pedagogy,' in S. M. C. Lau and S. Van Viegen. (eds): Plurilingual Pedagogies: Critical and Creative Endeavors for Equitable Language Education. Springer, pp. 303-21.

Lin, A. M. Y. 2020. 'From deficit-based teaching to asset-based teaching in higher education in BANA countries: Cutting through 'either-or' binaries with a heteroglossic plurilingual lens,' Language,' Culture and Curriculum 33: 203-12.

Lin, A. M. Y., Y. Wu, and J. L. Lemke, 2020. 'It takes a village to research a village': Conversations between Angel Lin and Jay Lemke on contemporary issues in translanguaging,' in S. M. C. Lau, and S. Van Viegen. (eds): Plurilingual Pedagogies: Critical and Creative Endeavors for Equitable Language Education. Springer, pp. 47-74.

Llompart, J., D. Masats, E. Moore, and L. Nussbaum. 2020. 'Mézclalo un poquito': Plurilingual practices in multilingual educational milieus,' International Journal of Bilingual Education and Bilingualism 23: 98-112.

Lopez, A. A., S. Turkan, and D. Guzman-Orth. 2017. 'Conceptualizing the use of translanguaging in initial content assessments for newly arrived emergent bilingual students,' ETS Research Report Series 2017: 1-12.

Lüdi, G. 2004. 'Pour une linguistique de la compétence du locuteur plurilingue [Towards a linguistics of the plurilingual speaker competence],' Revue Française de Linguistique Appliquée IX: 125-35.

May, S. 2014. The Multilingual Turn. Implications for SLA, TESOL, and Bilingual Education. Routledge.

Mazak, C. M, and K. S., Carroll Translanguaging in Higher Education: Beyond Monolingual Ideologies. Multilingual Matters 2016.

Moore, D. and L. Gajo. 2009. 'Introduction-French voices on plurilingualism and pluriculturalism: Theory, significance and perspectives,' International Journal of Multilingualism 6: 137-53.

North, B. and E. Piccardo. 2016. 'Developing illustrative descriptors of aspects of mediation for the common European framework of reference (CEFR),' Language Teaching 49: 455-9.

Nunnally, J. C. and I. H. Bernstein. 1994. Psychometric Theory. 3rd edn. McGraw-Hill.

Ortega, L. 2014. 'Ways forward for a bi/multilingual turn in SLA,' in S. May (ed.): The Multilingual Turn. Implications for SLA, TESOL and Bilingual Education. Routledge, pp. 32-53.
Piccardo, E. 2020. 'Plurilingualism: Vision, conceptuatlization, and practices,' in P. P. Trifonas and T. Aravossitas (eds): Handbook of Research and Practice in Heritage Language Education. Springer, pp. 207-25.

Prasad, G. 2014. 'Children as co-ethnographers of their plurilingual literacy practices: An exploratory case study,' Language and Literacy 15/3: 4-30.

Preece, S. and S. Marshall. 2020. 'Plurilingualism, teaching and learning, and Anglophone higher education: An introduction Anglophone universities and linguistic diversity,' Language, Culture and Curriculum 33: 117-25.

Rubio-Alcalá, F. D., J. L. Arco-Tirado, F. D. Fernández-Martín, R. López-Lechuga, E. Barrios, and V. Pavón-Vázquez. 2019. 'A systematic review on evidences supporting quality indicators of bilingual, plurilingual and multilingual programs in higher education,' Educational Research Review 27: 191-204.

Rymes, B. 2014. 'Communicative repertoire,' in B. Street and C. Leung (eds): Routledge Companion to English Language Studies. Routledge, pp. 287-301.

Savski, K. 2019. 'Putting the plurilingual/pluricultural back into the CEFR: Reflecting on policy reform in Thailand and Malaysia,' The Journal of AsiaTEFL 16: 644-52.

Schissel, J. L., H. de Korne, and M. LópezGopar. 2018. 'Grappling with translanguaging for teaching and assessment in culturally and linguistically diverse contexts: Teacher perspectives from Oaxaca, Mexico,' International Journal of Bilingual Education and Bilingualism 24: 340-56.

Stille, S. and J. Cummins. 2013. 'Foundation for learning: Engaging plurilingual students' linguistic repertoires in the elementary classroom,' TESOL Quarterly 47: 630-8.

Stratilaki, S. 2012. 'Plurilingualism, linguistic representations and multiple identities: Crossing the frontiers,' International Journal of Multilingualism 9: 189-201.

Taylor, S. K. and K. Snoddon. 2013. 'Plurilingualism in TESOL: Promising controversies,' TESOL Quarterly 47: 439-45.

Teddlie, C. and A. Tashakkori. 2006. 'A general typology of research designs featuring mixed methods,' Research in the Schools 13/1: 12-28.

Vallejo, C. and M. Dooly. 2020. 'Plurilingualism and translanguaging: Emergent approaches and shared concerns: Introduction to the special issue,' International Journal of Bilingual Education and Bilingualism 23: 1-16. 